with leucocytes while in others there were few or none. This is probably not related to the process at work in the particular case.

Another curious and disquieting finding was that not only did my conjunctival flap contain lymphocytes in nodules, but many sections showed large giant cells, so wide-spread had been the effect of the disease.

Since I have perforce been made familiar with the appearances found in sympathetic disease I have discovered similar changes in sections of an eye excised as probably dangerous last year. Unfortunately, there are no records on the case-sheet as to the history, etc., beyond the fact that it referred to a European male. Evidently I was lucky enough to excise the eye in time to prevent disease in the other eye, as no case of sympathetic disease has since been recorded.

It is probable that the reason for the case described being so insidious and free from redness, etc., was that it was a pure case of sympathetic disease without any endophthalmitis in the exciting eye.

\title{
CALCIUM DEFICIENCY IN THE BLOOD WITH REFERENCE TO SPRING CATARRH AND MALIGNANT MYOPIA
}

BY

\section{J. WOOD, CAPE TOWN}

FOR a good number of years I have been aware that some ocular conditions are associated with or caused by a deficiency in the amount of calcium in the blood, and I have treated cases empirically with good results, though I had not the means of ascertaining whether such deficiency really existed. I have now for some time been able to have this done through the kindness of Dr. L. Bosman, of the bio-chemistry department of the University of Cape Town, and it has been interesting to find that my expectations have been realised in all the cases where I was able to get the patient at a sufficiently early age.

The first cases to which my attention was drawn were sufferers from spring catarrh, and my early experiments were made with "afenil," a calcium chloride urea made by Knoll. I found that where the patients were young and the disease affected the pericorneal zone a cure could be effected in as little as three weeks by the giving of a 10 c.c. ampoule of afenil intravenously (one grm.) thrice in a week. The thickenings faded away and left only a narrow 
opacity near the edge of the cornea. Unfortunately the cure was not permanent, but that it was related to the treatment was shown by cases where repeated treatments produced disappearance of the thickening, in one case three times. The effect on spring catarrh affecting the lids was less satisfactory, but in these cases one had to deal with a grosser manifestation of the disease, where there was much epithelial hypertrophy, often extending deeply in the follicles, so as sometimes almost to be mistaken under the microscope for epithelioma. The follicle consists of a core of fibrous tissue with few cells, an intermediate area where numbers of plasma cells are found, with the endothelium of blood channels, and on the outside a thickened layer of epithelium usually showing some degenerative change. One was, however, able to convince oneself that in these cases there was also a real relation between the condition and a calcium deficiency, as treatment shortened the duration considerably.

For about a year I have had all cases examined as to the calcium content of the blood and in every case where the child was young enough a notable defect was revealed. The last three cases showed values of $9.3 \mathrm{mg}$., $8.9 \mathrm{mg}$., and $8.5 \mathrm{mg}$. per 100 c.c. of blood, in place of the normal for such ages, viz. $11 \mathrm{mg}$. By the time, however, that a child is into its 'teens the calcium deficiency appears to be made good.

For some years, however, one had learned that calcium administration alone is not much good, and that it should be combined with parathyroid extract. I confess to have had a disbelief in the administration of tiny doses of the parathyroid gland in the form in which patients could get it. This has been found to be quite erroneous, as the small amount of one tenth of a grain twice or thrice daily, without any other medicament will usually raise the calcium content to normal, or above it, in a few weeks. In most cases calcium lactate or kalzana has been administered as well.

As regards other treatment, occlusion of the eye is of great value. In cases of spring catarrh confined to the pericorneal site, and occurring in young children, occlusion, combined with parathyroid, will cause the disappearance of the swelling in two or three weeks, and if the blood calcium be watched and kept normal there should be no recurrence. Simple saline or boric acid irrigation is used to combat germ proliferation. In the lid cases the duration of the disease is shortened, the period of discomfort is reduced to months in place of years, though the nodules require a much longer time to vanish. I am unable to suggest the modus operandi of the calcium deficiency on the tissues. The trouble occurs at the period when the bones are beginning to make a great demand for lime salts, and as bones are most important from a developmental point of view they get their share and other tissues may be stinted. The possibility is that there is a want of endocrine balance between 
the glands such as the ovaries, whose hormone I am told by Dr. Bosman, permits the release of calcium from the blood, and that of the parathyroids which tends towards its retention. Spring catarrh might be defined as a reaction to climatic conditions-dryness, heat and dust-in young children where there is a deficient calcium content in the blood.

There is a difference in prognosis between the cases where the lids alone are affected in spring catarrh, and those where the disease is solely or largely pericorneal. The former are slower to get well, but do so entirely, so that in after years there is no visible trace left. In the latter, where the pericorneal change is considerable, there is a risk of the development of conical cornea. I am inclined to think that this cause of kerato-conus produces its effect rather quickly, but the final result is similar to what we ordinarily know as conical cornea, except that linear opacities are left at the margin of the cornea which last for a long period. I have recently seen an old spring catarrh patient where a plus $9.0 \mathrm{D}$. cyl. crossed with a minus $6.0 \mathrm{D}$. cyl. gave vision of $6 / 36$, a condition comparable with ordinary conical cornea results. Fortunately the other eye was less affected. If conical cornea may develop as part of a case of spring catarrh, an association beyond doubt, is it not very probable that the same aetiological factor is present in conical cornea which develops without it ? The age incidence is the same, and the period of cessation of rapid advance is similar. I have, moreover, just seen a case of very early conical cornea. The patient had been complaining of difficulties in vision for some time, and I got the additional information that she had been vaguely ill, had not menstruated for over six weeks, and that previously her periods had been irregular. Her eyes showed the characteristic retinoscopic appearances seen in kerato-conus of low degree, and her choice of lenses was quite different from my estimate. With weak convex cylinders she got $6 / 6$ nearly. Her calcium content proved to be the lowest I have found so far, viz., $7.2 \mathrm{mg}$. per 100 c.c.

In view of the fact that there has been no menstrual period this is very low, and one would expect that, if menstruation occurs soon, the calcium level would fall still lower. It will be interesting to watch this early case. I am of opinion that in all such cases there has been a general flabbiness and want of tone which suggests a deficiency of something. I do not think I have ever seen a case of conical cornea in a patient who was short in stature, but I have seen too few to say that the reverse is true, viz., that it occurs in patients whose bones have grown too fast. If we grant that the cornea has not got toughened up or has lost some of its toughness, we should expect that this, combined with a peripheral source of nutrition, would result in the curve with which we are familiar in kerato-conus. 


\section{Myopia}

If the cornea tends to give way in calcium deficiency, it is no long step to assume that the sclerotic may also give way, and that this may be associated with the advent of myopia. The condition is sufficiently common in youth for plenty of material to be available, and I have obtained proof in cases of rapidly advancing myopia in young children that the blood shows a calcium deficiency. Myopia is, however, a complex condition, and more than one factor is present. I have had several cases of high myopia in children of three years of age, and I have seen others, which though they were not recognised so young, had probably been in existence for a long time. The unexpected result in following up the cases was that in spite of one's fear the myopia did not increase, and the ophthalmoscopic picture was that of a fairly normal eye. For instance, many.years ago a child of two years and eight months was brought to me where there was as much as $13.0 \mathrm{D}$. of myopia. The greatest care was taken of the case, and I used to think that I had been the means of saving her eyesight. She saw Mr. W. Lang when she was half grown, and I have seen her lately, a tall young lady of more than twenty with vision of $6 / 4$ in each eye, no myopic changes and no increase of her original myopia. I have seen another case slightly younger, with minus $14.0 \mathrm{D}$. sph. This case I saw till she was seven without there being any change. It is not possible to put these cases into any category except congenital myopia, and I am satisfied that every now and then nature makes a myopic eye. The next cause is that the eyeball may grow normally beyond its correct dimensions. I have more than once seen a large family whose eyes when they were very young were nearly emmetropic and where one after the other have become myopic to a moderate degree. One such family, all girls, are now young women and are all myopic to about five dioptres. Similarly another family, now all grown up, came to me when young with from two to four dioptres of hypermetropia. They are now all within a fraction of emmetropia. Such cases change without one being in the least able to control them, but though there may be slight myopic changes in the fundus they never get seriously short-sighted.

In very sharp contrast with these are the cases where a child originally normal becomes rapidly myopic in the early years of life. My average record of these cases is that in spite of all care they advance up to adolescence and usually long past it. A full correction and apparently good health, with a proper reading range merely slow the advance but do not arrest it. Here we must admit that the sclerotic gives way, and we see the results of this reflected in the myopic character of the fundus, the thinned vitreous, and the danger of detachment. The sclerotic gives way as a result of some 
primary cause, and having become thinner, it may go on yielding even if the primary cause is no longer operative. Whatever may be said of the effect of eye muscle pressure, or of the effect of looking downwards at near work, one cannot class these as primary causes. If, however, we find an underlying factor which comes into play when growth begins to be rapid, and which produces a weakening of the sclerotic, then the difficulties in connection with the onset of myopia are largely solved. If calcium deficiency will result in bulging of the anterior part of the eyeball, why should it not do the same to the sclerotic. That it does so I think I have now proved, as in every case of myopia coming on quickly, and progressing I have found a calcium deficiency if the case was examined early enough.

The following are typical cases :-

Sheila R., aged 9 years, a thin tall child, just discovered to have defective vision. Right eye $-5 \mathrm{D}$. sph., left $-1.0 \mathrm{D}$. sph. with -1.5 D. cyl. Calcium content found to be only $7.5 \mathrm{mg}$. per 100 c.c. This case went up to $12 \mathrm{mg}$. in six weeks on parathyroid treatment only.

Richard R., a child with hereditary myopia in the family, was brought for blepharitis. Aged 9 years and 6 months. Each eye had -2 D. sph. with $-0.5 \mathrm{D}$. cyl. Calcium content $8.5 \mathrm{mg}$.

Willy K., aged 4 years, rather neglected. Right eye -7 D.sph. with $1 \mathrm{D}$. cyl., left eye $-6 \mathrm{D}$. sph. with $1.5 \mathrm{D}$. cyl. Calcium content $8.5 \mathrm{mg}$.

Rosie L., aged 9 years, hereditary myopia. Right eye -6 D. sph. with -3 D. cyl., left eye -5 D. sph. with -3 D. cyl. Calcium content $9.5 \mathrm{mg}$. This went up to $12 \mathrm{mg}$. in a few months, but on stopping the treatment it dropped to $10 \mathrm{mg}$. No increase in myopia in the time.

Bernard F., aged 9 years. Six months ago he was first seen, but his blood could not be examined. Since then the right eye has gone up from-1.0 D. sph. to - 3.5 D. sph. and the left eye from $-6.0 \mathrm{D}$. sph. to $-8.5 \mathrm{D}$. sph. Calcium content is $9.8 \mathrm{mg}$.

Doreen B., aged 7 years. Right eye -15.0 D. sph., left eye 14 D. sph. with -1 D. cyl. Calcium content $8.9 \mathrm{mg}$. This case had also old disseminated choroiditis in each eve.

Harry B., aged 6 years. Brought for blepharitis. Right eye 4.0 D. cyl., left eye +1 D. sph. with -3 D. cyl. Calcium content $8.0 \mathrm{mg}$.

In only one case a different result was obtained.

Sidney $\mathrm{H}$., aged 12 years. Each eye $-15 \mathrm{D}$. The child was extremely small for his age, and was a seven months' baby. Vision was only $6 / 18$, but there was hardly any myopic change in the fundi. Calcium content $13 \mathrm{mg}$. Evidently we were either too late, and the demand for calcium by his bones had been small, or it may have 
been a case of congenital myopia. All that I could get from his mother was that he had always been ill. This case can hardly be considered an exception to the rule.

I have records of a number of other cases but those quoted will suffice.

In all up to the age of 12 years, a calcium deficiency has been found. After that age the calcium content appears to become normal.

South Africa is a very large country and the difficulty of seeing cases at regular intervals is likely in the future to prevent me from seeing the effects of treatment. It would therefore seem desirable not to wait, but to give those in large centres the chance of testing my views and watching the results. It will be in any case a matter of years to discover if we can prevent the further advance of myopia in early cases.

It would seem obvious that cases of congenital myopia, and growth myopia will be for ever beyond other than optical treatment. If, however, my observations are confirmed generally, then it would seem to be a reasonable hope that cases of malignant myopia with its disastrous results should be preventable. An early blood examination where there is known to be a hereditary tendency to high myopia should reveal the advent of danger, and treatment should prove an eftective prophylactic.

I hope to be able to record the results of treatment as time passes.

\section{Note by L. P. Bosman, D.Sc.}

It is an established fact that administration of parathyroid gland, not necessarily in conjunction with calcium salts, causes an increase in the calcium content of the blood. A few cases have been cited in the earlier part of this communication having relation to myopia, where the blood calcium went up from deficiency to normal in a short period. As an example in other complaints I may quote the following: Mrs. W., a young lady, aged 24 years, suffering from severe headaches, was found to have a calcium level of only $7.5 \mathrm{mg}$. Placed on one tenth grain of parathyroid for a month her headaches disappeared, and her calcium content was found to be $11.9 \mathrm{mg}$. The treatment was stopped and in another month she had dropped to $9.8 \mathrm{mg}$., and her headaches were as bad as ever. With renewed treatment they again disappeared and the calcium level went up again to $12.0 \mathrm{mg}$. per 100 c.c.

Mr. L., aged 42 years, suffering from ununited fracture. Calcium content only $6 \mathrm{mg}$. Treated with parathyroid. In a month the calcium level was $12 \mathrm{mg}$. Treatment discontinued for two months produced fall to $7.5 \mathrm{mg}$. Renewed treatment restored it to $11 \mathrm{mg}$.

The method of estimation is a modification of Tisdall and Kramer. About 7 c.c. of blood are drawn from an arm vein and set aside 
without any coagulant. The serum separates out well in twentyfour hours.

Two c.c. of the serum are transferred to a centrifuge tube, and to it are added 2 c.c. distilled water, a few drops of 2 per cent. ammonia, and 1 c.c. of a saturated solution of ammonium oxalate. The contents are thoroughly mixed by rotation and set aside for at least 45 minutes. The tube and its contents are next centrifuged at 2,000 revolutions for three minutes. This results in the calcium oxalate produced in the above reactions being closely and firmly packed at the bottom of the tube. The supernatant fluid is carefully poured off and the tube allowed to drain by inverting it over dry filter paper for five minutes. Two c.c. of 2 per cent. ammonia are now added and the tube again centrifuged and drained as before. Two c.c. of normal sulphuric acid are now added and the tube placed in a beaker of water is now heated to about $80^{\circ}$ Cent. The contents are then titrated with $\mathrm{N} / 100$ potassium permanganate solution in a micro-burette till a faint pink tinge is left. The solution must be freshly prepared for each new set of estimations. One c.c. of $\mathrm{N} / 100$ solution of potassium permanganate corresponds to $10 \mathrm{mg}$. of calcium.

\title{
A CASE OF SYMPATHETIC INFLAMMATION ASSOCIATED WITH INTRAOCULAR SARCOMA
}

BY

\author{
T. HARrison ButLer \\ BIRMINGHAM \\ with a pathological note by \\ J. JAMESON Evans \\ BIRMINGHAM
}

CASES of sympathetic inflammation following an intraocular sarcoma in the fellow eye have been reported by Fuchs, Meller, and others, but must be of extreme rarity. The following example of this complication seems therefore worthy of record.

Miss H., aged 20 years, came to the Coventry Hospital on December 8, 1924, and was found to be suffering from severe irido-cyclitis in both eyes. She gave the history that the right eye had been inflamed for five weeks, the left for six weeks. She was quite positive that the left eye began to give trouble before the right. A month previously she had facial paralysis on the left side but this had completely disappeared when she was first seen. There was no history of any headache or vomiting. There had been slight 